Zagazig J. Agric. Res., Vol. 43 No. (1) 2016

\title{
PYRIDALYL INSECTICIDE RESIDUES IN TOMATO PLANTS
}

\author{
Mahmoud M. Ramadan*, M.A. El-Tantawy, M-B.A. Ashour and R.M. Sherif \\ Plant Protection Dept., Fac. Agric., Zagazig Univ., Egypt.
}

\begin{abstract}
Field experiment was conducted to determine residues of pyridalyl insecticide on tomato leaves and fruits. Tomato plants were sprayed with the insecticide pyridalyl (Pleo 50\% EC) at the rate of 100 $\mathrm{ml} /$ fad. on January, 2014. QuEChERS (catchers) method was used for extraction and clean-up of the samples. Residues were determined 2 hours, 1, 2, 3, 5, 7, 10 and 14 days post-treatment using UHPLC-UV. The recovery percentages were 89.29 and $96.73 \%$ for leaves and fruits, respectively. The results revealed that the residue concentrations of pyridalyl on leaves and fruits, two hours after single application of the insecticide were 1.007 and $0.815 \mathrm{mg}$ a.i. $/ \mathrm{kg}$, respectively. The insecticide residues on fruits were $0.707,0.569$ and $0.474 \mathrm{mg}$ a.i. $/ \mathrm{kg}$ after 1,2 and 3 days and reached $0.2 \mathrm{mg}$ a.i./kg after 14 days. The corresponding residues on leaves were $0.808,0.646,0.637$ and $0.284 \mathrm{mg}$ a.i./kg after 1, 2, 3 and 14 days. The rates of degradation ( $\mathrm{k}$ values) were 0.100 and 0.115 on leaves and fruits, respectively. The corresponding half-life times (t 0.5) were 6.950 and 6.050 days on leaves and fruits, respectively. The residues on tomato fruits were below the maximum residual level (MRL) value reported by the European Food Safety Authority (EFSA, 2013). Thus, tomato fruits could be safely harvested for human consumption and for processing purposes.
\end{abstract}

Key words: Pyridalyl, Pleo, residues, QuEChERS, tomato, UHPLC.

\section{INTRODUCTION}

Pesticides from a broad range of classes that are widely used in various combinations and/or at different stages of cultivation, and during post-harvest storage to protect crops against pests, and/or to provide quality preservation. Pesticide residues that remain in the food supply could pose a risk for human health because of their potential subacute and chronic toxicity. Therefore, residues of pesticide could affect the ultimate consumers especially when freshly consumed (Abou-Arab, 1999). Moreover, Food Inspection Agencies require improved sensitive and confirmatory methods to monitor pesticide residues in fruits and vegetables to ensure the safety of food supply.

Tomato is one of the most important vegetable crops in Egypt, which considered the world's fourth largest producer of tomato (FAO, 2010). The average yield in Egypt per faddan is relatively low, this may be due to many factors, including insect infestation. Tomato used for consumption as fresh product produced under greenhouse conditions as well as in open fields (Ugurlu Karaagac, 2012).

Pyridalyl is an insecticide invented and developed by Sumitomo Chemical Co. Ltd. This insecticide exerts effective control against lepidopterous and thysanopterous pests on cotton, vegetables and fruits (Sakamoto et al., 1995; Sakamoto and Umeda, 2003) Also, pyridalyl is safe for useful arthropods like parasitoids and predators, hence is a suitable tool for compositional management of pests as well as management of pest resistance. Due to its short occurrence period and low impacts on environment, pyridalyl may be used as a selective poison against most of pests without generating phytotoxic effects. Pyridalyl was registered in some Asian countries in 2002, including Japan (Sakamoto et al., 2003;

\footnotetext{
* Corresponding author: Tel. : +201111259587

E-mail address: mmramadan@ez.edu.eg
} 
Sakamoto et al., 2005; Sato, 2010), and it is permitted for use in Africa. The chemical starts to be broadly used in Egypt. The mode of action of pyridalyl is inhibition of cellular protein synthesis in insect, but not mammalian (Moriya et al., 2008). Hrouzková et al. (2012) showed that the QuEChERS method is simple and exhibits acceptable levels of sensitivity and accuracy to fulfill the requirements of pyridalyl residue analysis.

The aim of the present study is to determine residues of the insecticide pyridalyl on tomato leaves and fruits at different intervals after application under open field conditions and calculate the rate of degradation to get data required for sanitary, phytosanitary standards as well as assessment the health risk of exposure. Thus, the safety of food supply could be ensured.

\section{MATERIALS AND METHODS}

\section{Chemicals}

Pyridalyl (Pleo ${ }^{\circledR} 50 \%$ EC) and analytical standard pyridalyl (95.3\%) were kindly supplied by Sumitomo Chemical Co. Ltd.<smiles>FC(F)(F)c1ccc(OCCCOc2c(Cl)cc(OCC=C(Cl)Cl)cc2Cl)nc1</smiles>

IUPAC name: 2,6-dichloro-4-4 (3,3dichloroallyloxy) phenyl-3-[5-(trifluoromethyl) - 2- pyridyloxy] propyl ether.

Other chemicals and reagents of analytical grade were used such as: acetonitrile, HPLC grade (POUCH SA, Gliwice, Poland); acetic acid (El Nasr Pharmaceutical Chemicals Co., Abu-Zaabal, Cairo, Egypt); primary secondary amine (PSA), graphitized carbon black (GCB), $\mathrm{C} 18$, anhydrous magnesium sulfate (MgSO4) and anhydrous sodium acetate for QuEChRs kits purchased from Agilent Technologies Co., USA).

\section{Field Treatment and Sampling}

Field trial was carried out under completely randomized blocks design with three replicates, plot dimensions were $6 \times 7 \mathrm{~m}^{2}$ at Dakados village, Mit Ghamr district, Dakahlia Governorate,
Egypt on January 12, 2014. Tomato seedlings (Lycopersicon esculentum Mill.) cultivar 2006TY (Newstar Company) were transplanted in open field. Common agricultural and fertilization practices were used. At the beginning of fruits mature stage, the plants were sprayed with pyridalyl recommended rate (100 $\mathrm{ml}$ pyridalyl 50\% EC/fad.) using backpack sprayer (capacity $20 \mathrm{l}$ ). After the insecticide application, tomato plants didn't receive any foliar applications until the end of experiment.

Representative leaf and fruit samples were collected randomly from the experimental plots at $0,1,2,3,5,7,10$ and 14 days after insecticide application. The leaves collected from different levels of plant while fruit samples were also collected from mature fruits that represent the consumed edible part. Samples were collected for recovery test before pesticide application, then transferred to laboratory in one kg plastic bags. Each sample was blended. Ten grams of the blended sample was transferred to a $50 \mathrm{ml}$ polypropylene centrifuge tube, labeled and stored at $-18^{\circ} \mathrm{C}$.

\section{Extraction and Clean up Procedure}

Pyridalyl residues were extracted and cleaned up by QuEChERS modified method according to Lehotay (2007) and Raczkowski et al. (2011). In this method, $10 \mathrm{~g}$ of the blended sample were transferred to $50 \mathrm{ml}$ polypropylene centrifuge tube, $15 \mathrm{ml}$ of acetonitrile, containing $1 \%(V / V)$ of acetic acid, were added. The sample was shaken manually for one minute hardly and vortexed for $15 \mathrm{sec}$. Then extract powder include: $6 \mathrm{~g}$ magnesium sulphate and $1.5 \mathrm{~g}$ anhydrous sodium acetate were added to the centrifuge tube contents, mixed manually for one minute and vortexed for $15 \mathrm{sec}$, then centrifuged for $5 \mathrm{~min}$ at $4000 \mathrm{rpm}$. Eight milliliters of the resulted supernatant were transferred to a $15 \mathrm{ml}$ centrifuge tube. This tube contains required materials for purifying including: $400 \mathrm{mg}$ PSA and $1200 \mathrm{mg}$ magnesium sulphate, in addition to, $10 \mathrm{mg}$ GCB for leave samples, no GCB was add to fruit samples. Then the sample was shaken immediately manually for one min, vortexed for $30 \mathrm{sec}$ and centrifuged for $5 \mathrm{~min}$ at $5000 \mathrm{rpm}$. Afterwards, $5 \mathrm{ml}$ of the upper layer were taken by pipette and poured into a clean tube. These 
prepared samples were stored frozen until final quantitative determination.

\section{Quantitative Determination Procedure}

One microliter of the previously prepared sample was injected to a UHPLC-UV Agilent USA model 1290 infinity with binary pump, vwd, autosampler. The mobile phase consisted of $60 \%$ acetonitrile: $40 \%$ distilled water. Pyridalyl was detected at $208 \mathrm{~nm}$ (Farouk et. al., 2014).

\section{Recovery Assay}

Recovery assay was performed using untreated tomato fruits and leaves. The samples were homogenized before being spiked with one $\mathrm{mg} / \mathrm{kg}$ concentration. The samples were processed for extraction, clean up and quantitative final determination according to the above mentioned procedure.

The obtained recovery percentages were 89.29 and $96.73 \%$ for leaves and fruits, respectively. The results were corrected according to the recovery values.

\section{Kinetic Study}

The rate of degradation and half-life period of pyridalyl was calculated according to Gomaa and Belal (1975), Ashour (1976) and Gomaa et al. (1979). The relationship between the logarithm of concentration of pyridalyl residues and time intervals were plotted. A straight line was fitted using excel trend line with intercept equal to logarithm of initial concentration, and the slope of the line was calculated. Accordingly, the rate of degradation $(k)$ of pyridalyl and the half-life period (t 0.5 ) of the insecticide were calculated as follows:

\section{Rate of degradation $(k)=2.303 \times$ slope}

Finally, the half-life period (t 0.5 ) can be obtained from the following equation:

$$
\mathrm{t}_{0.5}=0.693 / \mathrm{k}
$$

\section{RESULTS AND DISCUSSION}

Pyridalyl residues on leaves and fruits after single application of the insecticide on the mature stage of tomato plants at the rate of 100 $\mathrm{ml} / \mathrm{fad}$. are presented in Table 1 . The residue concentrations were 1.007 and $0.815 \mathrm{mg}$ a.i. $/ \mathrm{kg}$ after 2 hours post-treatment on leaves and fruits, respectively. The percentages of dissipation on tomato leaves were 19.762, 36.743 and 54.618\% after 1,3 and 7 days from application, respectively. The corresponding percentages of dissipation on fruits were 13.251, 41.840 and $59.509 \%$. Fourteen days after application, pyridalyl residues reached 0.284 and $0.200 \mathrm{mg}$ a.i./kg on the tomato leaves and fruits, respectively. The corresponding percentages of dissipation were 71.797 and $75.460 \%$.

The logarithms of pyridalyl residue concentrations on tomato leaves and fruits were plotted against time after application (Figure 1). The data felt very closely on straight lines, in accordance with the requirements of a first order reaction, in which the rate of reaction is directly proportional to the concentration of the insecticide. Accordingly, the slope value, rate of degradation $(\mathrm{k})$ of pyridalyl and the half-life period (t 0.5) of the insecticide were calculated as mentioned before and presented in Table 2.

The $\mathrm{k}$ values were 0.100 and 0.115 on tomato leaves and fruits, respectively. The corresponding t 0.5 values were 6.950 and 6.050 days. The $\mathrm{k}$ value of the insecticide was lower on leaves than on fruits. Subsequently, the t 0.5 value was higher on leaves than on fruits. The higher deposits on leaves compared with fruits may due to larger exposed surface area on leaves than that on fruits as the later are always hidden under leaves. The rate of loss was higher on fruits in comparison to leaves. The differences in the loss of the initial residues on leaves and fruits reflect the titer of metabolizing enzymes in plants as well as the effect of growth dilution of the residues (Hill et al., 1982).

In a study where Phe- ${ }^{14} \mathrm{C}$-pyridalyl and Pro${ }^{14} \mathrm{C}$-pyridalyl were applied to tomato plants (cultivar: Bush Beefsteak), 4 times at $224 \mathrm{~g}$ ai/ha (i.e., 78 days, 43 days (5-7 leaves stage), 22 days and 1 day before harvesting, respectively). It was found that residues on the mature tomato collected 7 days after the final treatment were $0.085-0.172 \mathrm{mg} / \mathrm{kg}$, and those after washed off were $0.056-0.135 \mathrm{mg} / \mathrm{kg}$. Major ${ }^{14} \mathrm{C}$ residue on the mature tomatoes was the unchanged form pyridalyl metabolism in tomatoes (GLP study) (Anonymous, 2004). Hrouzková et al. (2012) 
studied the dissipation of pyridalyl on spring onions and strawberries following an application of $238 \mathrm{ml} \mathrm{a.i./ha}$ and reported that initial deposits were less than $3 \mathrm{mg} / \mathrm{kg}$, which declined to $1 \mathrm{mg} / \mathrm{kg}$ in 7 days, with half-lives of 0.27 and 5.99 days, respectively. The higher residues on strawberries were probably due to the difference in surface area. Spray retention on onion leaves can also be difficult because of the vertical nature of the plant. Yoon et al. (2013) studied the dissipation of pyridalyl on cauliflower following an application of $200 \mathrm{~g}$ a.i./ha. They reported initial deposits of $0.43 \mathrm{mg} / \mathrm{kg}$, which declined to $0.12 \mathrm{mg} / \mathrm{kg}$ in 10 days, with half-life time of 7.74 days. Farouk et al. (2014) studied the dissipation of pyridalyl on tomato treated with the recommended dose. They reported initial deposits of $0.953 \mathrm{mg} / \mathrm{kg}$, which declined to not detected in 14 days, with half-life time of 22.56 days.

Table 1. Residues of pyridalyl on tomato leaves and fruits

\begin{tabular}{lcccc}
\hline $\begin{array}{l}\text { Hours or days after } \\
\text { treatment }\end{array}$ & $\begin{array}{c}\text { Leaves } \\
\text { (mg a.i./kg) }\end{array}$ & Loss (\%) & $\begin{array}{c}\text { Fruits } \\
\text { (mg a.i./kg) }\end{array}$ & Loss (\%) \\
\hline $\mathbf{2}$ hours & 1.007 & 0.00 & 0.815 & 0.00 \\
$\mathbf{1}$ day & 0.808 & 19.762 & 0.707 & 13.251 \\
$\mathbf{2}$ days & 0.646 & 35.849 & 0.569 & 30.184 \\
$\mathbf{3}$ days & 0.637 & 36.743 & 0.474 & 41.840 \\
$\mathbf{5}$ days & 0.519 & 48.461 & 0.378 & 53.620 \\
$\mathbf{7}$ days & 0.457 & 54.618 & 0.330 & 59.509 \\
$\mathbf{1 0}$ days & 0.398 & 60.477 & 0.254 & 68.834 \\
$\mathbf{1 4}$ days & 0.284 & 71.797 & 0.200 & 75.460 \\
\hline
\end{tabular}
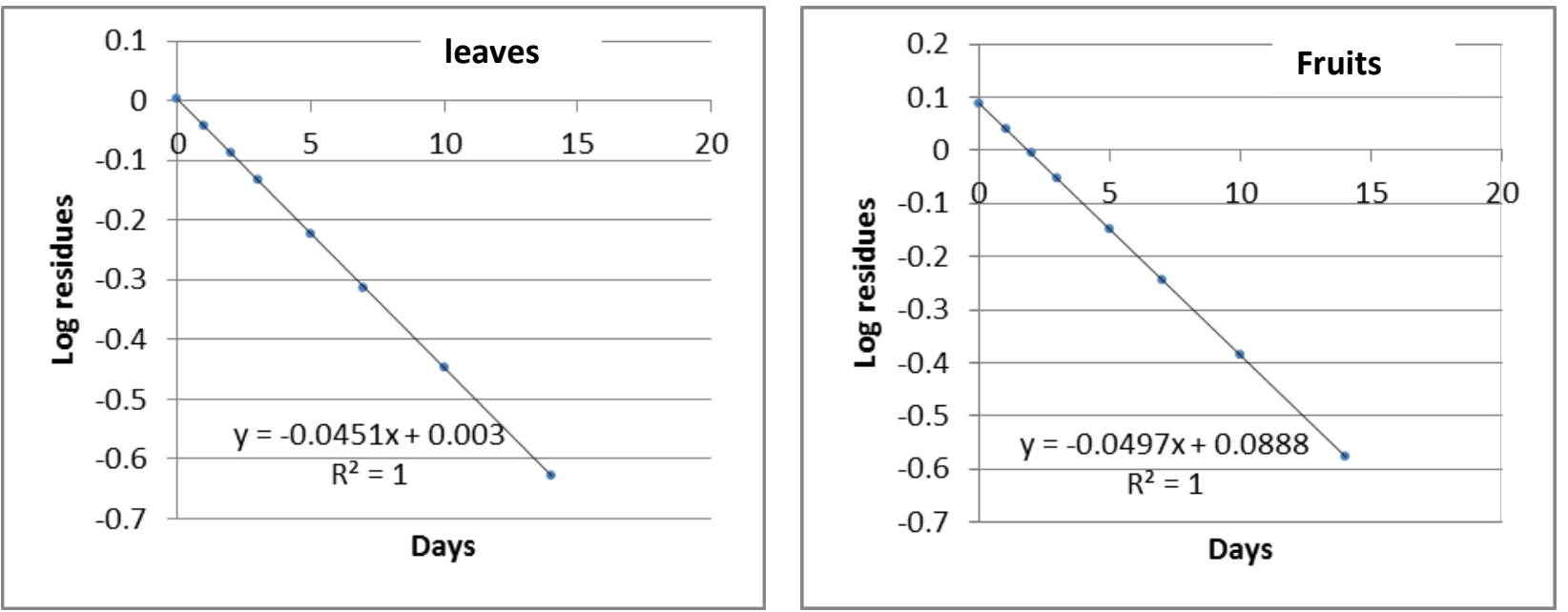

Fig. 1. Regression lines of logarithm pyridalyl residue concentrations versus days after application on tomato plant

Table 2. Slope, rate of degradation and half-life time of pyridalyl on tomato

\begin{tabular}{lcc}
\hline Parameter & Leaves & Fruits \\
\hline Slope & 0.043 & 0.050 \\
Rate of degradation (k) & 0.100 & 0.115 \\
Half-life t 0.5 (days) & 6.950 & 6.050 \\
\hline
\end{tabular}


Adverse effects on human health of pesticides residues remaining in food after application may be cause health risk due to pesticide residues in the diet. The lowest no observable adverse effect level (NOAEL) for pyridalyl was $2.80 \mathrm{mg} / \mathrm{kg}$ b.w./day, based on two-generations reproductive toxicity tests in rats. Therefore, a safety factor of 100 was applied to calculate ADI, thus yielding 0.028 mg/kg b.w./day (Anonymous, 2004).

Pyridalyl maximum residue limit (MRL) in tomato was $1.5 \mathrm{mg} / \mathrm{kg}$ according to European Food Safety Authority (EFSA) (2013). Regarding the data obtained from the present study, the residue concentration of pyridalyl on tomato fruits $(0.707 \mathrm{mg}$ a.i. $/ \mathrm{kg})$ one day after single application at the recommended rate was below the above-mentioned EFSA MRL value. Thus, tomato fruits could be safely harvested for human consumption and for processing purposes.

\section{REFERENCES}

Abou-Arab, A.A.K. (1999). Behavior of pesticides in tomatoes during commercial and home preparation. Food Chemistry, 65: 509-514.

Anonymous (2004). Evaluation Report Pyridalyl. Food Safety Commission Pesticides Expert Committee, January 14.

Ashour, M-B.A. (1976). Residual effect of certain soil pesticides on some field crops. M.Sc. Thesis, Fac. Agric., Zagazig Univ. Egypt.

European Food Safety Authority (EFSA), (2013). Conclusion on the peer review of the pesticide risk assessment of the active substance pyridalyl. EFSA Journal, 11 (8): 3240.

FAO (2010). www.tutaabsoluta.com/news.

Farouk, M., L.A. Hussein and N.F. EL-Azab (2014). New HPLC and fluorometric methods for the determination of pyriproxyfen and pyridalyl insecticide residues in tomatoes. Journal oF AOAC International, 97 (1): 188-196.
Gomaa, E.A. and M.H. Belal (1975). Determination of dimethoate residues in some vegetables and cotton plants. Zagazig J. Agric. Res., 2 (2): 215-220.

Gomaa, E.A., M.H. Belal and M-B.A. Ashour (1979). Influence of Temik (aldicarb) on herbicide persistence in cultivated cotton field soil under field conditions. Bulletin of Environ. Contamination and Toxicol., 22: 717-725.

Hill, B.D., W.A. Charnetski, G.B. Schaalje and B.D. Schaber (1982). persistence of fenvalerate in alfalfa: effect of growth dilution and heat units on residue half-life. J. Agric. Food Chem., 30 (4): 653-657.

Hrouzková, S., M. Andraščiková, S.B. Abdel Ghani and Purdešová (2012). Investigation of levels and fate of pyridalyl in fruit and vegetable samples by fast gas chromatography-mass spectrometry. Food Anal. Methods, 6: 969-977.

Lehotay, S.J. (2007). Determination of pesticide residues in foods by acetonitrile extraction and partitioning with magnesium sulfate: collaborative study. J. AOAC Int., 90 (2): 485-520.

Moriya, K., S. Hirakura, J. Kobayashi, Y. Ozoe, S. Saito and T. Utsumi (2008). Pyridalyl inhibits cellular protein synthesis in insect, but not mammalian, cell lines. Archives of Insect Biochem. and Physiol., 69: 22-31.

Raczkowski, M., A. Holodynska, A. Nowacka and B. Gnusowski (2011). Application of the QuEChERS method for determination of pesticide residues in tomato samples using GC-NPD/ECD. Progress in Plant Prot., 51 (2): 727-731.

Sakamoto, N., S. Matsuo, M. Suzuki, T. Hirose, K. Tsushima and W.O. Umeda ( 1995). Patent 9611909; Chem. Abstr., 125, 114466.

Sakamoto, N. and K. Umeda (2003). Research and development a novel insecticides of pyridalyl. Fine Chemicals, 32 (20): 35-44.

Sakamoto, N., S. Saito, T. Hirose, M. Suzuki, S. Matsuo, K. Izumi, T. Nagatomi, H. Ikegami, K. Umeda, K. Tsushima and N. Matsuo (2003). The discovery of pyridalyl: a 
novel insecticidal agent for controlling lepidopterous pests. Pest Manag. Sci., 60: 25-34.

Sakamoto N., N. Ueda, K. Umeda, S. Matsuo, T. Haga and T. Fujisawa (2005). Research and development of a novel insecticide “pyridalyl”. Sumitomo Kagaku, 1: 1-14.

Sato, S. (2010). USDA Foreign Agricultural Service, GAIN report No. JA 0029.
Ugurlu Karaagac, S. (2012). The current status of Tuta absoluta (Meyrick) (Lepidoptera: Gelechiidae) in Turkey and base-line toxicity of some insecticides. Bulletin OEPP/EPPO, 42 (2): 333-336.

Yoon J.Y., J.H. Park, H.R. Moon, G.T. Han and K.S. Lee (2013). Residue patterns of indoxacarb and pyridalyl in treated cauliflower. Agric. Sci., 4 (3): 111-116.

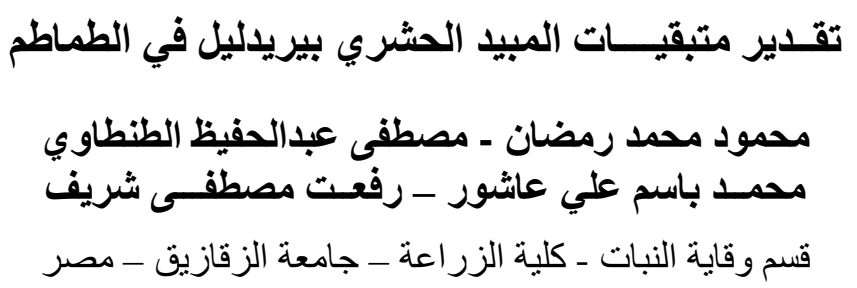

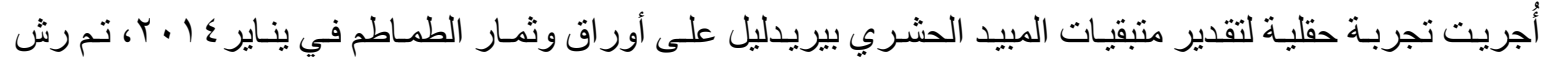

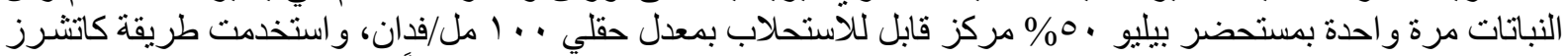

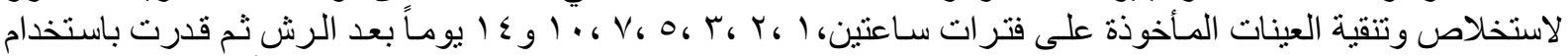

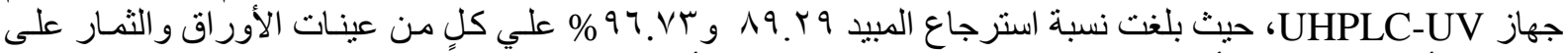

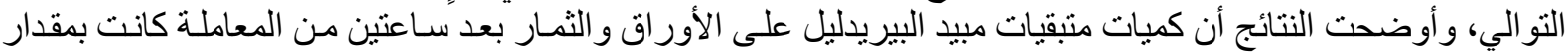

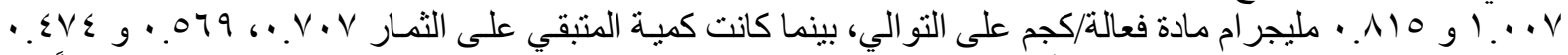

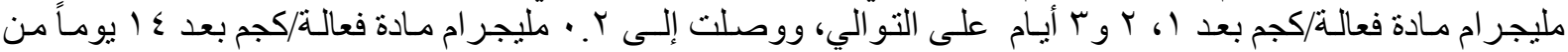

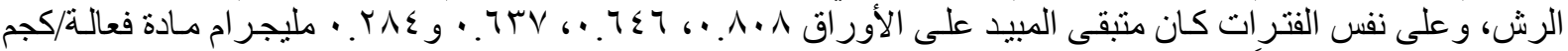

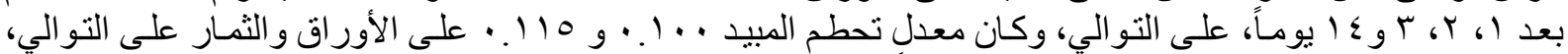

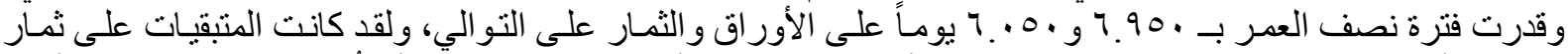

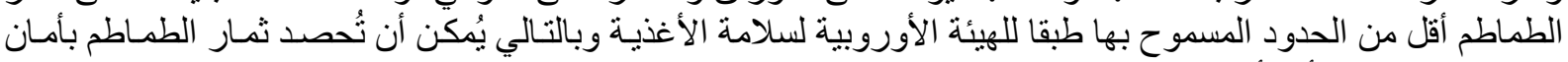
للاستهلاك البشرى أو لأغر اض اض التصنيع. 